\title{
COMPOSIÇÕES ENFERMAS - DOENÇA, CRÍTICA E MÚSICA EM THOMAS MANN
}

\author{
Diego Rogério Ramos* \\ ramos.drr@gmail.com
}

\begin{abstract}
RESUMO Nas obras de Thomas Mann, a doença não se coloca como um elemento simples do entrecho, mas sim como uma parte central da evolução da trama, especialmente no desenvolvimento dos personagens. No entanto, em suas obras, as figurações da saúde e da doença não são fixas, e, portanto, faz-se necessário buscar um núcleo de sentido a essas noções. Argumentamos que a contraposição fundamental entre os termos é a expressão de uma tensão entre o desenrolar da vida com suas expectativas normais e uma força disruptiva que abala essa estrutura. Trata-se de desenvolver os termos dessa contraposição, apresentando algumas imagens de seus romances, a partir do que poderemos expor a dimensão crítica da doença como noção filosófica. A seguir, apresentaremos alguns momentos do romance "Doutor Fausto", de Mann, tendo por objetivo explorar a estrutura crítica dessa noção e a forma como opera. Finalmente, tomaremos a música, um dos temas centrais do romance de Mann, como modelo para a análise dessa crítica possível. A partir disso, poderemos apresentar os o limite dessa concepção de doença como dispositivo crítico, especialmente no debate artístico do século $X X$.
\end{abstract}

Palavras-chave Thomas Mann, doença, crítica, música.

ABSTRACT In Thomas Mann's works, illness cannot be seen as a simple plot element, but rather as a central part of the story's evolution, especially concerning the characters' development. However, the figurations of health and illness are not fixed and, therefore, it is necessary to seek a nucleus of

* USP Univ. de São Paulo, São Paulo/SP - Brasil. Artigo recebido em 31/08/17. Aceito em 19/10/17.

KRITERION, Belo Horizonte, no 139, Abr./2018, p. 109-132 
meaning to these notions. We would argue that the fundamental contraposition between these terms is the expression of a tension between the unfolding of life with its normal expectations and a disruptive force that shakes this structure. It is a question of developing the terms of this contraposition, exploring some images of Mann's novels, from which we can expose the critical dimension of illness as a philosophical concept. Then, we will present a few moments of Mann's Doctor Faust, in order to explore the critical structure of this notion and the way it operates. Finally, we will take music, one of the central themes of Mann's novel, as a model for the analysis of this possible criticism. Based on that, we can present the limits of this conception of illness as a critical device, especially within the artistic debate of the twentieth century.

Keywords Thomas Mann, illness, critic, music.

\section{Parte 1 - A noção de doença em Thomas Mann}

Nas séries dicotômicas que compõem os tradicionais juízos filosóficos, as posições das noções de saúde e doença seriam facilmente dispostas: a primeira delas seria colocada na série do belo, do justo, do bom e, claro, da vida; enquanto a doença se aproximaria do feio, do injusto, do mau e da morte. Essas posições estariam implícitas, por exemplo, na consideração de Ariston de Quios: “A virtude é a saúde da alma”, pois revelaria a continuidade entre essas noções. Nesses termos, a doença estaria sempre comprometida com a limitação dos homens, de sua força e de suas possibilidades de desenvolvimento. No entanto, alguns autores reservam uma posição privilegiada para a doença, uma disposição que a estabelece como núcleo gerador de crítica. Nossa intenção neste artigo é mostrar alguns aspectos dessa disposição, tomando como objeto de análise a obra de Thomas Mann. Com isso, poderemos apresentar a estrutura de operação crítica da noção de doença, conforme elaborada pelo escritor, especialmente no que se refere à crítica que a arte é capaz de empreender quando movida pela doença.

Mais do que um elemento de entrecho de seus romances, contos e novelas, a doença tem uma função central em diversas obras de Mann e opera como uma dobra fundamental no desenvolvimento dos personagens. No entanto, a caracterização dessa dobra não é constante. Um breve levantamento do aparecimento da doença em algumas das ficções de Mann pode ilustrar a variedade de formas tomadas pela doença em suas obras.

Podemos nos lembrar de "Morte em Veneza", novela publicada em 1912, que narra a história de Gustav Von Aschenbach, um escritor com seus 50 anos 
que decide viajar para a cidade italiana, mais ou menos como uma forma de lidar com sua crise criativa. Nessa história, o adoecimento de Aschenbach parece acompanhar uma gradual transformação de caráter. Essa transformação fica tanto mais evidente se aproximamos dois momentos da história. No início de sua viagem, o escritor vê um grupo de jovens espirituosos e, entre eles, um senhor fortemente maquiado, com dentes e cabelos postiços, tentando omitir sua idade muito mais avançada do que a de seus companheiros. Diante dessa cena, Aschenbach faz um juízo grave a respeito daquele senhor, até mesmo enojado pela maneira como ele escondia sua idade. No fim da obra, próximo de sua morte, é o próprio Aschenbach quem frequenta diariamente um salão para ser barbeado, maquiado e penteado. Note-se, então, que a doença não se expressa apenas pela deterioração física, mas também pela gradual mudança de caráter, em especial na relação que Aschenbach estabelece com a paixão. Obcecado, ele busca compulsivamente a visão do jovem Tadzio. E mesmo que sempre tente ser discreto, essa obsessão aumenta conforme a doença progride. Ainda não deixa de ser desprovido de interesse notar o silêncio e a sutileza da doença, tanto no personagem quanto em Veneza, onde autoridades e cidadãos insistem que não há um surto de cólera na cidade. Enfim, em "Morte em Veneza", a doença parece possibilitar a desinibição do personagem, uma forma de entrega dionisíaca à paixão. A doença fez Aschenbach render-se ao excesso de uma forma que antes ele não havia experimentado.

Outra figuração essencial da doença nas obras de Mann pode ser encontrada em "A montanha mágica", romance publicado em 1924. Aqui, o protagonista Hans Castorp sai das planícies, onde logo iniciaria uma carreira na construção de navios, para visitar um primo doente no sanatório em Davos, nos Alpes suíços. Enquanto estava lá, ele próprio começa a apresentar sintomas de tuberculose e acaba permanecendo no sanatório por 7 anos. Nesse romance, a doença opera, de forma literal e metafórica, como uma força de interiorização e afastamento. Literalmente, pois a doença é o que determina a internação no sanatório, lugar isolado e distante; e metaforicamente, porque a estada naquele lugar faz com que Hans Castorp adquira uma nova forma de apreensão da vida, baseada grandemente no desenvolvimento espiritual que teve no lugar. Thomas Mann declarou que o romance de formação seria justamente a sublimação e espiritualização dos romances de aventura ${ }^{1}$ e que, com Wilhelm Meister de

1 Em uma conferência ministrada a estudantes de Princeton sobre seu romance "A montanha mágica", Mann declarou: "Und was ist denn wirklich der deutsche Bildungsroman, zu dessen Typ der "Wilhelm Meister" sowohlwie der "Zauberberg" gehören, anderes, als die Sublimierung und Vergeistigung des Abenteuerromans?" (MANN, Einführung in den Zauberberg Für Studenten der Universität Princeton. In: T. Mann, T. Der Zauberberg, Berlin: S. Fischer Verlag, 1952). Apesar dessa declaração, a concepção dessa obra como um romance de 
Goethe, "A montanha mágica" poderia ser qualificada como um Bildungsroman. Assim, poderíamos compreender todas as conversas, paixões, casos e sentimentos como as "aventuras" que conformaram o caráter e a disposição de Hans Castorp, lembrando que teria sido a doença o que serviu como o combustível da disposição de se afastar da vida da planície, com todas as normas e estruturas, com sua ordem apolínea e destinos duramente estruturados, em benefício de uma dedicação ou uma entrega a forças mais noturnas, individuais, espirituais, forças da montanha que se contrapõem efetivamente à ordem da planície.

Em uma pequena novela intitulada "A enganada", publicada em 1954, pouco antes de sua morte, Thomas Mann apresenta a história de Rosalie Von Tümmler, história na qual a doença, novamente, figura como chave do entrecho. Rosalie é uma viúva com aproximadamente 50 anos de idade que começa a perder a jovialidade por causa do "fenômeno orgânico do seu momento de vida", a menopausa. A viúva contrata um tutor americano de inglês para seu filho e se apaixona por ele, mas receia essa paixão justamente por sua idade e pela condição de seu corpo. Algum tempo depois, passado desfrutando dessa paixão apenas em suas fantasias românticas, seus sangramentos retornam e ela toma isso como o sinal de rejuvenescimento necessário para aceitar o amor pelo jovem. Um rejuvenescimento que seria tanto corporal quanto espiritual, pois sua relação com o mundo se renova, especialmente com a natureza. Mais do que nunca, ela assume um caráter romântico, concebendo o mundo em caracteres quase mitológicos, insistindo no erotismo do ciclo de vida e morte. Um tempo depois, no entanto, descobrimos que o sangramento vaginal fora causado por um câncer em seu útero que se espalhou pelo seu corpo e a levou à morte. O motivo do rejuvenescimento foi, na verdade, a doença que a transformou, revigorou e, por fim, a fez perecer mais rapidamente do que poderia esperar.

O tema da doença acompanhou toda a experiência intelectual e artística de Mann. Mesmo em sua primeira grande obra, "os Buddenbrooks", corre subrepticiamente entre as gerações uma disposição cada vez mais enferma. Nas quatro gerações retratadas, podemos notar que os bem-sucedidos comerciantes paulatinamente se afastam das expectativas sociais e burguesas, tomando cada vez mais um caráter espiritual e interior, o qual os tornam cada vez mais

formação não é inconteste, e até mesmo Thomas Mann, em carta de 23 de julho de 1924 a Felix Bertaux e de 25 de maio de 1926 a Ernst Fischer, afirmou que essa sua obra se definiria como uma paródia do romance de formação. Referindo essas outras concepções, lembraríamos que mesmo a noção de paródia guarda um significado de primeira importância para o quadro criativo de Mann, e que, relacionando-a à ironia e à montagem como procedimentos de construção, poderíamos reconhecer que a paródia de um romance de formação manteria elementos dessa sua qualificação e seria mesmo uma peculiar "modernização" dessa forma literária. Desenvolvemos alguns desses aspectos em nossa dissertação de mestrado, intitulada "Os Lamentos da Razão - Mito e História de Doutor Fausto de Thomas Mann". 
avessos ao papel quase dinástico que a família detinha na pequena cidade onde moravam. Se essa decadência poderia figurar como metáfora para um adoecimento transgeracional da família, no personagem Hanno Buddenbrook a doença deixa de ser metafórica. O jovem é afligido por infecções recorrentes e constantes, e uma grave dificuldade de cicatrização, fazendo com que ele não pudesse desfrutar integralmente de uma sociabilidade normal.

Note-se, em todas essas histórias, e em tantas outras, a doença não é apenas um fenômeno que se soma ao drama do entrecho, mas verdadeiramente fundamenta a estrutura dessas ficções, repõe as formas da relação entre os personagens e seus meios. Na tentativa de descobrir um núcleo essencial à noção de doença a partir do modo como ela operou na vida desses personagens de Mann, poderíamos propor uma definição nos seguintes termos: a doença é a força disruptiva que abala a relação dos homens com o mundo. Isso quer dizer que, enfermos, esses personagens se afastam, ou recusam inteiramente, o cumprimento das expectativas sociais, de tal forma que mesmo o anelo à estrutura normativa do todo social se perde. Aschenbach recusa, de forma espontânea ou forçada, a decisão racional de voltar à sua cidade e de escrever em benefício de alimentar sua obsessão com o jovem Tadzio. Hans Castorp se afasta paulatinamente das expectativas da vida de engenheiro na planície, nega o cumprimento das normas sociais comuns, o casamento, a família, o trabalho, o "sucesso", em benefício de uma vida na montanha, nesse ambiente mágico de reflexão e formação individual. Rosalie Von Tümmler nega as imposições de sua idade e de sua posição social, e deseja terrivelmente o calor da juventude, de uma vida amorosa e de beleza quase irreais. Tudo isso revela como Thomas Mann compreende e elabora a doença como essa força disruptiva da estrutura social aparente, que afasta o indivíduo do que é comum e gregário.

Se aceitamos essa definição, podemos partir a um segundo momento deste trabalho. Trata-se de apontar o caráter crítico da doença, efetivamente, como se constrói, a partir dessa disposição individual e desagregadora, a força de uma crítica cultural, social e artística. Para tanto, vou me ater às imagens dispostas em "Doutor Fausto", um dos últimos romances de Mann, escrito entre 1943 e 1947. A escolha desse romance como elemento fundamental da economia argumentativa deste artigo se deve ao papel central da doença na trama e à possibilidade de mostrar tanto o caráter crítico dessa noção quanto o limite estrutural dessa crítica. Por se tratar de uma obra literária, é importante que nossa análise não se autonomize do romance. Por isso, procederemos por meio da análise de alguns trechos da história de Mann, intercalando considerações de ordem filosófica, tentando garantir, com isso, que nossos conceitos não percam a sensibilidade do material e que o potencial filosófico das imagens do romance se tornem mais claras. 
Em "Doutor Fausto", a doença aparece como o catalisador do demoníaco e seria, portanto, o instrumento da destinação de Adrian Leverkühn, o protagonista da obra de Mann, figurado como o músico que desenvolveu o dodecafonismo. A noção de destino pode ser compreendida conforme a apresentação de Walter Benjamin, que designaria uma acepção muito mais material do que se estaria acostumado a conceber em relação ao termo. Ela definiria o desdobramento quase inevitável que se segue a um caráter determinado, quase como se tratássemos do desenvolvimento esperado de um tipo literário, cuja descrição é capaz de revelar aspectos não apenas do caráter, mas também da função literária no interior de uma obra. Exemplar disso seria a vida do próprio Adrian Leverkühn, o Fausto de Mann, cujo caráter inteligente, inelutavelmente desencantado e alheio ao mundo parece determinado ao pacto. Ressoando a estrutura de uma inevitabilidade mítica, o Fausto de Mann apresenta em seus últimos momentos de consciência, em um discurso elaborado no último capítulo do romance, uma análise da própria história, apontando como a infelicidade e sofrimento que caracterizam sua vida seriam sinais de uma destinação demoníaca. É o próprio personagem, portanto, que possibilita interpretar o esvaziamento valorativo que compunha sua vida e a forma como ele era incapaz de criar vínculos significativos com qualquer um ou qualquer coisa como a evidenciação daquele desenlace fatal. Nesses termos, o destino seria a expressão do mito, a expressão da continuidade de formas de vida estáveis e normatizadas. Note-se que a série de qualificativos que utilizamos para caracterizar Adrian Leverkühn denotam o que talvez seja sua grande marca: o sofrimento. E se estamos tratando de doença, a relação se faz evidente. O sofrimento é a expressão da doença, é sua manifestação mais tangível. Em toda sua vida, Adrian Leverkühn sofreu, não apenas pelo seu caráter alheio, solitário, desiludido, desencantado, mas também por graves crises de cefaleia que o atingiam frequentemente. Mas ainda não é essa a doença que o caracteriza fundamentalmente.

Na história de Mann, Adrian Leverkühn abandona o curso de Teologia para estudar música. Para isso, transfere-se para Leipzig. Quando chegou à cidade, contratou o carregador de malas da estação ferroviária como guia. Foram para igrejas, monumentos, edifícios públicos e locais de interesse turístico. Ao fim do passeio, Adrian Leverkühn pediu ao carregador que o levasse a um lugar no qual poderia fazer uma refeição. O carregador o levou até a porta de um lugar, garantindo que aquela era uma "boa locanda", em suas palavras, e despediram-se. Era um casarão, no qual o compositor foi acolhido por uma senhora com gestos quase pudicos, que o conduziu até o salão principal. Ali, Adrian Leverkühn foi recebido pelos olhares concupiscentes de várias mulheres; as cortesãs que esperavam trocar seus corpos e seu tempo por dinheiro. $\mathrm{O}$ velho carregador 
de malas havia conduzido o músico ingênuo a um bordel. Acuado, Leverkühn percebe um piano, um amigo naquele lugar que lhe era tão estranho. Após alguns acordes, uma das mulheres aproximou-se e acariciou a face do músico com o braço. O jovem saiu apressado do lugar. Mais de um ano se passou até que o orgulho de Adrian Leverkühn cedeu ao instinto (Trieb), e ele voltou àquele casarão em busca da prostituta que o acariciou, a quem ele chamava de Esmeralda. Avisaram-lhe que ela não trabalhava mais naquele local devido a uma hospitalização. Descobriu onde ela morava e, obcecado, foi à casa da mulher, que se situava em outra cidade. Esmeralda lembrava-se do visitante, e, grata e lisonjeada pela viagem que o músico empreendera em sua busca, $o$ preveniu contra ela: "Da boca dele, soube a mulher que a viagem a Pressburg fora feita por sua causa - e para demonstrar-lhe sua gratidão, acautelou-o contra seu próprio corpo" (Mann, 2000, p. 217-s). Esmeralda advertiu Adrian contra sua doença. O músico, no entanto, insistiu na consumação do ato sexual, e ali o músico contraiu sífilis, doença que o acompanhou pelo resto de sua vida e que o caracteriza fundamentalmente. Interessa destacar a especificidade dessa relação entre Adrian e Esmeralda: quando o músico se une à prostituta, ele uniu a transgressão ao castigo, pois, consciente da doença da mulher, o pecado da carne tornou-se magicamente a fonte de seu suplício. Com isso, notamos que a imagem composta por essa relação é, em si mesma, carregada de tensões: pecado e castigo, condenação e salvação, amor e violência, vida e doença compõem o enlace amoroso entre Adrian Leverkühn e Esmeralda - músico e prostituta. No entanto, esse enlace amoroso, a aceitação da doença, é também o momento em que se firmou o pacto entre Leverkühn e o demônio, figura que se apresentaria apenas anos mais tarde para explicar o acordo estabelecido entre os dois naquela noite com Esmeralda. Toda aquela tensão evidente na imagem desse pecado de amor é um catalisador para o enlace entre o músico, sujeito moderno e esclarecido, e o demônio, figura encantada. Nos termos de uma dialética do esclarecimento, poderíamos destacar esse enlace amoroso, que traz em seu bojo o demoníaco, como o momento de ambiguidade dialética entre racionalidade e mitologia. E assim, a doença parece ser o limiar que evidencia essa ambiguidade, pois é justamente essa contaminação dialética que deve ser ressaltada. ${ }^{2}$ Para compreender essa relação entre a doença e o demoníaco, nos

2 A melhor forma de tomar o romance talvez não seja pelos termos da tensão entre esclarecimento e mito, mas sim entre história e mito. Mito seria a força de estabilização que restringe a vida em uma estrutura existencial específica, cujas esferas de valor são normatizadas e legitimadas de forma mais ou menos unívoca; a História, por outro lado, seria a força de superação das categorias estruturadas, que procede pelos rompimentos com as práticas de vida e os conhecimentos estabelecidos em benefício da dissolução dos mitos. História é o devir, enquanto mito é o mundo naturalizado. Note-se: se o mito é a vida nos termos que aparece e é estruturada, 
aproximamos da obra apresentando uma carta de Leverkühn ao amigo Zeitblom, narrador do romance de Mann. Ali o Fausto explica as condições em que se encontrava no dia da aparição demoníaca:

O dia inteiro, lastimosa criatura que sou, fiquei deitado no escuro com minha maldita cefaleia. Diversas vezes, quase me sufoquei e tive que vomitar, como ocorre em casos de acessos violentos, mas ao anoitecer, inopinada e repentinamente, houve uma melhora. Pude reter a sopa que me trouxe a mãe Manardi (“Poveretto!”). Também esvaziei em seguida com bom ânimo uma taça de vinho tinto ("Bevi, bevi!") e de repente me senti tão seguro que nem sequer me recusei um cigarro (Mann, 2000, p. 314).

A certa altura da noite, o compositor sente algo inteiramente inesperado.

Ei que de chofre me sinto ferido por um golpe de frio cortante, como se a gente estivesse sentado no inverno numa sala bem aquecida e subitamente alguém abrisse uma janela que deixasse entrar a temperatura gélida de fora. No entanto, aquilo não vinha de trás, lá onde se acham as janelas, senão me atacava de frente (Mann, 2000, p. 315).

O diabo se apresenta ao músico. O momento de presentificação é emblemático, pois a crise de cefaleia expressa, como um sintoma do espírito, a situação enferma em que se encontra aquele sujeito. $\mathrm{O}$ termo crise, em sua raiz semântica latina crǐsis, designa o momento de mudança súbita, o momento decisivo da doença, do qual poderia decorrer a vida ou a morte do doente. Em sua derivação grega, o termo designava o momento de separar, decidir ou julgar. Assim, podemos considerar que doença e crise integram uma mesma constelação, e representam justamente a relação de tensão que o doente tem com a vida. A crise doentia parece ser a manifestação de um momento crítico, uma ocasião para o surgimento de algo diverso; poderíamos dizer, a manifestação de um devir. A doença, nesses termos, poderia ser vista como uma fase necessária da vida humana. Rosenfeld, em uma análise sobre a doença nas obras de Thomas Mann, sintetiza:

Esse espírito "doentio" é um elemento importante para a superação da vida em si fechada e sem perspectivas humanas, é uma força que, opondo-se ao simples funcionar dos reflexos, é capaz de dizer "não" à mera biologia, para usarmos a expressão de Max Scheler. Mas é precisamente em virtude desse afastamento e dessa distância que o homem consegue apossar-se de um modo mais profundo da vida (Rosenfeld, 1994, p. 149-s).

tanto a doença quanto o próprio demoníaco podem, virtualmente, ser detentores de uma potencialidade histórica. Essa tensão entre mito e história pode ser encontrada em diversas obras de Mann, e em "Doutor Fausto" possibilita a compreensão de aspectos os mais diversos no interior da obra e na sua relação com seus materiais. 
E se a doença, como a crise, coloca em um ponto crítico a vida do enfermo, como se a partir dela restasse ao Fausto apenas a possibilidade de romper com essa vida, precisamos lembrar a especificidade da sífilis, a doença de Leverkühn, que Thomas Mann tratou com delonga em um texto sobre Nietzsche:

A evolução de Nietzsche não é outra coisa senão a história de uma desinibição e degeneração paralíticas - um movimento de ser levado além de uma normalidade altamente talentosa rumo às esferas gélidas e grotescas de um conhecimento mortal e de uma solidão moral, um grau terrível e criminoso de conhecimento para o qual esse homem delicado e bondoso, dependente de todo tipo de cuidados, não tinha sido nascido, mas para o qual, assim como Hamlet, fora convocado (Mann, 2011, p. 121).

A doença põe uma distância entre o homem e as imposições da vida, removendo o fardo do normal; ela conduziria o doente a um lugar no qual um novo olhar sobre o mundo pode ser lançado, um olhar desimpedido pelas determinações da saúde. No entanto, enquanto crise, esse momento de suspensão da doença conduz o sujeito a uma fronteira, a partir da qual poucos passos podem ser dados para a renovação da vida ou para uma existência moribunda e assassina. Assim, mais do que indicar a iminência da reversão do esclarecimento em superstição e mito, a doença parece conduzir o Fausto a um momento de ruptura, no qual se encontram tensionados mito e história. E o demônio surge para dominar essa ruptura. Com isso, faz-se necessário analisar a doença de Leverkühn conforme foi apresentada pelo diabo, a fim de compreender seu conteúdo na vida do Fausto.

Inicialmente, Adrian Leverkühn não acredita na aparição. O Fausto crê que a figura diante dele e o frio que dela emanava eram resultados de um delírio induzido pela doença, por um acesso febril. Contra essa descrença, o Diabo argumenta: “- Santa lógica! Justamente o contrário está certo. Eu não sou nenhum produto do foco em tua pia mater, lá em cima, mas o foco te capacita - compreendes? - a avistar-me, e sem ele, indubitavelmente, não me enxergarias" (Mann, 2000, p. 330).

A doença, diz o demônio, é o que possibilita o encontro entre os pactuários. Dessa forma, propomos considerar que a doença é constituída menos por um elemento intrinsecamente mal e demoníaco do que por uma condição em relação à vida, que possibilita ao doente ver algo distinto. Em si mesma, essa condição parece ser amoral e determinaria apenas uma forma de lidar com a vida, uma forma desafiadora ou desobediente que rompe as expectativas de normalidade. Assim, o mal não está colado à situação de suspensão própria da doença, e o doentio não é necessariamente uma expressão do demoníaco. Tudo se passa como se o doente, cujos vínculos com a vida estão enfraquecidos, pudesse quebrar a 
ordem normativa, jogar com ela. Isso quer dizer que a doença se opõe à vida, mas não a abandona. Nos termos da aparição demoníaca:

A doença, e em especial uma doença escandalosa, discreta, oculta, produz certa oposição crítica ao mundo, à vida mediana; deixa as pessoas revoltadas e irônicas, com relação à ordem burguesa, e faz com que suas vítimas procurem a proteção do espírito livre, de leituras, de pensamento (Mann, 2000, p. 327).

Parece-nos pertinente elaborar a afinidade entre essa noção de doença e o conceito benjaminiano de limiar. Schwelle, o limiar, é uma zona de transição ou um lócus de hibridismo, no qual a definição das identidades é comprometida. Mas, diferente de uma fronteira, que é uma linha de separação entre os termos, o limiar é uma ampla linha de união. Em alemão, seguindo uma etimologia de Benjamin, o limiar teria relação com o verbo schwellen, que pode ser traduzido por inchar ou intumescer, cuja proximidade ao campo da doença é evidente. Mas o que esse processo inflamatório da doença indicaria? O que essa zona une? A doença une vida e morte, ou seja, ela é o lugar no qual a tensão entre vida e morte fica mais forte e indistinta. Reconhecendo a influência de Nietzsche sobre Mann, não é sem interesse apontar como a maneira que o filósofo aborda a noção de doença pode enriquecer nossa concepção. A definição de saúde, segundo Nietzsche, não pode ser realizada com sucesso, e todas as tentativas de fazê-lo fracassaram "miseravelmente". Isso porque uma verdadeira compreensão se apoiaria em uma série de determinantes estabelecidos pelo indivíduo: "depende do seu objetivo, do seu horizonte, de suas forças, de seus impulsos, seus erros e, sobretudo, dos ideais e fantasias de sua alma" (Nietzsche, 2001, §120). A saúde da alma deveria ser tomada da mesma maneira, e o ideal de um padrão de saúde deveria ser abandonado. Nesses termos, a consideração de Ariston de Quios, "A virtude é a saúde da alma", seria reescrita como "sua virtude é a saúde de sua alma", e o virtuoso faria apenas insistir nas características que definem sua própria saúde. Com essas considerações, Nietzsche propõe refletir se realmente poderíamos prescindir da doença, e chega mesmo a afirmar que a "exclusiva vontade de saúde não seria um preconceito, uma covardia e talvez um quê de refinado barbarismo e retrocesso". Segundo Nietzsche, podemos considerar o mundo como vontade de potência (Der Willezur Macht) (cf. Nietzsche, 1992, §36), e a grande saúde seria a situação de transbordamento de forças do homem, na qual todas as coisas que se antepõem a ele seriam enfrentadas de tal forma que o sofrimento que delas deriva não seria sinal de fraqueza, mas de força. Nessa vida extremamente saudável, a morte tem uma presença mais forte, pois esses grandes enfrentamentos seriam tanto mais perigosos quanto mais ousado fosse esse homem. Para esse tipo de homem, a doença não é degeneração, mas 
a situação na qual sua força pode bem se expressar, e designa a situação da qual derivam múltiplas possibilidades de mudança.

Se a doença é uma aproximação à morte, e esta é a expressão da finitude das coisas, de sua falibilidade, da possibilidade de mudança e ruptura, então o doente teria a capacidade de escapar às exigências normativas e às expectativas vitais do homem. No entanto, o diabo quer capturar o sentido da morte:

Que significa "morto", desde que a flora brota e viceja em muitas cores, sob as mais diversas formas, e até se apresente heliotrópica? Que significa "morto", desde que a gota demonstra aquele apetite sadio? A resposta definitiva à questão de saber o que é mórbido e o que é são, meu filho, não a deveríamos abandonar aos beócios. Sempre resta duvidoso se estes têm a opinião certa acerca da vida. Frequentemente, a vida já apanhou com avidez o que se originou na estrada da morte ou da doença, e serviu-se disso, a fim de ir mais longe e subir mais alto. Já esqueceste o que te ensinaram na escola da Sapiência, a saber, que Deus pode converter o Mal no Bem e que não convém admitir que ele perca a oportunidade de fazê-lo? Item, é necessário que alguém tenha sido doente ou louco, para que os demais não precisem sê-lo (MANN, 2000, p. 330).

A aparição demoníaca insiste que a morte é apenas um fenômeno contínuo à vida. $\mathrm{O}$ que é mais significativo, a morte cultivaria a vida, em uma eterna repetição e continuação, como se fossem efetivamente indiferentes, pois se articulam intima e necessariamente. Note-se que essa opinião sobre a natureza da morte acompanha uma especulação sobre Deus, especulação que insiste em tornar indistintos bem e mal, pois, ao "converter o Mal no Bem”, não é a redenção ou o perdão que são experimentados, mas uma confusão entre esses princípios teológico-morais. Ora, isso parece revelar aspectos a respeito de o que seria o demoníaco, quais seriam as características do diabo pensado por Mann. A operação de tornar ambíguos bem e mal parece ser o modo de ação desse diabo, ao menos nesse momento histórico, em que ele se apresenta a Leverkühn. O demônio tem consciência do tempo, e reconhece que a influência direta do mal e do caos era um modo de operação particularmente efetivo em outras épocas:

Lembra-te da comovente exaltação, do ambiente bem convulsivo, cheio de pressentimentos e inquietudes: o afã de peregrinar ao Santo Sangue de Niklashausen, no vale do Tauber, as cruzadas de crianças, as hóstias sanguinolentas, a fome, a revolta dos camponeses do Bundschuh, a guerra e a peste em Colônia, meteoros, cometas e grandes signos, freiras estigmatizadas, cruzes que assomavam nas vestes das pessoas, que então queriam combater os turcos, com o estandarte feito de uma camisa de mocinha, adornada de uma cruz milagrosa. Que belos tempos, tempos endiabradamente alemães! (Mann, 2000, p. 326). 
No entanto, no século XX, a influência do diabo parece trabalhar com ferramentas mais sutis para causar seu mal. A doença seria para o demônio uma abertura:

Para ser breve: a metaespiroquetose é o processo meningeal, e podes acreditar que precisamente os pequerruchos têm verdadeira paixão pelas partes superiores, têm predileção pela região da cabeça, as meninges, a dura mater, que envolve o cérebro, e a pia mater, que junto com ela, protege o seu interior o delicado parênquima; pois, desde o momento da primeira contaminação geral, apaixonadamente, enxameiam nessa direção (Mann, 2000, p. 328).

A influência do demônio é mesmo microscópica, como ele diz sobre o processo inflamatório da Spirochaeta Pallida. Sua intenção seria apenas a de capturar o "conteúdo" da doença em benefício de conformar a vida do doente, pois, como a própria aparição afirma, o diabo nada cria, e pode apenas transformar o que já é criado, potencializar ou minimizar a matéria que já existe no mundo:

Onde nada existe, o próprio Diabo não terá campo, e nenhuma Vênus pálida produzirá coisa alguma que preste. Nós não criamos novidades, que isso cabe a outra gente. Limitamo-nos a desatar e libertar. Mandamos às favas a lerdeza, a timidez, os castos escrúpulos e as dúvidas (Mann, 2000, p. 333).

Dessa forma, o demônio utiliza a infecção sifilítica para aparecer ao seu eleito, e toma a doença para afetar sua vida. Os efeitos da doença tornam-se a única experiência do Fausto: uma perpétua oscilação entre extremos que impossibilita a vida comum; os acessos febris seguidos de calafrios são os extremos de uma só experiência doentia de algo que já existia na vida do Fausto. Nessa passagem entre extremos, tudo que é comum torna-se indiferente, pois não pode ser propriamente experimentado. Além da evidente relação com aquele esforço especulativo de tornar ambíguos o bem e o mal, essa perpétua oscilação pode explicar a frieza de Adrian Leverkühn, pois os sintomas da doença parecem motivar o afastamento do músico das pessoas e das expectativas sociais, seu ascetismo. Ao tornar ambíguas aquelas noções teológico-morais, ou ao afastar-se de contatos sociais, parece-nos estar em operação um mesmo princípio, uma mesma força de desarticulação e negação.

Ora, a força de desarticular a normatividade poderia ser tomada a partir das exigências de expor a falsidade do que é tomado por natural, lançar luz sobre as fissuras do mito e possibilitar o surgimento da história. Isso quer dizer que, sem outras considerações, poderíamos julgar que o demônio, ao tornar ambíguos bem e mal e motivar a frieza de Leverkühn, faria um bom serviço ao homem, pois possibilitaria justamente a superação da situação mítica na qual o músico se encontrava; o demônio, aqui, faria justiça ao seu nome Lúcifer, 
seria efetivamente o Portador da Luz. Mas esse não é o caso. O demônio toma a doença e faz de seu conteúdo uma expressão do próprio inferno. Note-se a continuidade entre os efeitos da doença e a destinação infernal. Em vida, o músico oscilaria entre o calor extremo e o frio congelante. O calor da "inspiração deveras deleitosa, fascinante, indubitável, férvida", pelo qual não seria capaz de interromper o próprio trabalho para qualquer outra coisa; e o frio do maior tédio, da esterilidade mais completa, da inteira incapacidade de criar. Após essa vida doente, a alma do Fausto estava destinada ao mesmo fardo, eternamente:

No fundo, o Inferno será apenas uma continuação da tua vida excêntrica. Para resumir tudo em poucas palavras: sua quinta-essência, ou se preferes outro termo, sua peculiaridade característica consiste em deixar aos seus habitantes unicamente a escolha entre o mais extremo frio e um calor tão intenso que até poderia derreter granito. Entre esses dois estados, correm eles de cá para lá, ululando, pois, enquanto se encontram num deles, o outro sempre se lhes afigura celestial alívio. Porém imediatamente, também esse se tornará insuportável, na acepção mais infernal do adjetivo (Mann, 2000, p. 347).

São nesses termos que devemos pensar o diabo, ou seja, pelos efeitos que ele impõe ao homem por meio da doença, pelo destino que lhe determina. Mas vale insistir no reconhecimento da isenção moral da doença, que não é inelutavelmente ligada ao demoníaco. Efetivamente, o sofrimento pode ser interpretado tanto como a evidenciação de um destino - como se as dores e a infelicidade antecipassem a condenação - quanto pode ser compreendido como um sintoma que denuncia o mito - como se revelasse a inverdade do destino aparente e as possibilidades do devir.

Tendo apresentado essa concepção específica de doença, seu potencial crítico e revelador da crise, podemos agora elaborar como ela opera no romance, especificamente sobre a arte.

\section{Parte 2 - Doença e crise na música}

Adrian Leverkühn era um artista, representante dessa que Mann considerava a mais alemã de todas as artes: a música. Isso dá ensejo a um profundo debate estético, tanto no que se refere à dinâmica interna da arte - da música, através da trama, mas também da literatura, pela forma com que o romance é construído - quanto de sua relação com a sociedade e a política. Esse debate presente no romance expõe de forma exemplar a situação da arte no século XX. Efetivamente, Adrian Leverkühn reconhece a peculiar situação da arte em seu tempo, a crise de legitimação na qual se encontrava. Podemos lembrar a pergunta que o jovem Adrian dirige a seu professor de música: "Por que me parece inelutavelmente que quase todos, não, que todos os recursos e convenções da Arte hoje só 
prestem paródias?” Confessando, em seguida, que é uma pergunta retórica, cuja resposta ele pode apenas esperar de alguém (Mann, 2000, p. 188-s). O jovem estudante de música reconhece que, na vida moderna, a arte perdeu a dignidade e sentido próprios que antes detinha, pois não consegue mais comunicar um valor socialmente compartilhado. Dessa maneira, à música, racionalizada e desencantada, ${ }^{3}$ restaria apenas silenciar ou realizar paródias de si mesma, no esforço de reconstituir uma dignidade perdida. Isso não significa o "fim da arte", mas sim que ela deve aceitar uma nova caracterização do mundo, ou estaria fadada ao anacronismo e à paródia, como Adrian percebe. Justamente porque compreende essa situação, ele faz um esforço desmedido para construir uma nova forma de composição. É o reconhecimento dessa condição da arte - situação verdadeiramente generalizada da cultura - que determina em Leverkühn o anseio fáustico. A criação do dodecafonismo 4 é apresentada no romance como o resultado desse esforço desmedido de Leverkühn. E justamente por ser um método composicional inteiramente novo, desmedido em relação à tradição, que ele pode ser figurado como oriundo de uma crise e, no romance, ser associado ao demoníaco e resultante do pacto.

Essa crise artística seria expressão de uma crise espiritual mais ampla, fazendo do debate estético um debate cultural e político. Aqui seria importante destacar o paralelo: a doença de Leverkühn tem o mesmo caráter dessa crise cultural, que poderia mesmo ser designada como uma situação de patologia social. A música e o compositor seriam os objetos privilegiados para apresentar essa situação. Podemos lembrar como, desde muito cedo, Thomas Mann reconhecia na música sua potência extraestética. Em "Considerações de um Apolítico", 5 Mann argumenta em favor da Alemanha e contra as democracias ocidentais dizendo que seu país tinha uma cultura cujo fundamento estrutural poderia

3 Esses termos devem ser compreendidos conforme elaboração de Max Weber (cf. "Ética protestante e o Espírito do Capitalismo; Ciência e Política - duas vocações") - e desenvolvimento posterior de Adorno e Horkheimer em Dialética do Esclarecimento.

4 No romance de Mann, o dodecafonismo foi criado por Leverkühn, fato que foi explicitado na segunda edição da obra, na qual o autor inseriu uma nota ao fim do livro: "Não me parece supérfluo avisar o leitor que o gênero de composição descrito no capítulo XXII e conhecido sob a denominação de técnica dodecafônica ou serial, é realmente propriedade intelectual de um compositor e teórico contemporâneo, Arnold Schoenberg".

5 Um trabalho produzido durante a Primeira Guerra Mundial, "Betrachtungen eines Unpolitischen" (Reflections of a Nonpolitical Man, 1983), é um grande ensaio no qual o autor tematiza as condições da cultura alemã. Mann enxergava que a essência do caráter alemão, representado por Lutero, Goethe, Nietzsche, Wagner e outros, seria ameaçada pelos ideais democráticos e civilizatórios próprios à França ou à Inglaterra. Ele concebia que uma nação se assemelha a um organismo, e a melhor maneira de se conservar seria a fidelidade à sua própria natureza. No caso alemão, a sobrevivência da Alemanha adviria da lealdade ao caráter musical não democrático. Pode-se ver na obra um Thomas Mann nacionalista e conservador, que agradou os partidos da direita alemã. No entanto, mesmo durante a concepção da obra, a visão política do autor parece alterarse, e a ironia que toma a obra revela a desconfiança em relação àqueles princípios, que mais tarde seriam revisados ou abandonados. 
se ligar mais à música do que a princípios sociais. Isso quer dizer que, muito mais do que princípios políticos tradicionais, os efeitos da música, como sua capacidade de arrebatamento dionisíaco, de motivação sem conceitos, ou de descolamento individual compunham o motor da cultura alemã. Em "Doutor Fausto", a música opera como o sinal dos tempos, pois a crise musical apresenta a crise da cultura. Mas mais do que isso, a música seria uma arte cujo efeito sobre a alma dos homens é da maior grandeza, podendo ser benevolente ou perniciosa. No romance "A montanha mágica", Settembrini afirmava: "Há na música um elemento perigoso, senhores. Insisto no fato da sua natureza ambígua. Não exagero ao declarar que ela é politicamente suspeita" (Mann, 1980, p. 131-s). A música é uma arte não representativa, isenta de imagens, bem como é desprovida de palavras. Isso quer dizer que a música não é visível nem conceitual. A partir disso, é notável como a suspeita sobre a música é reposta pela Filosofia. Em sua terceira crítica, Kant afirma que a música não reserva nada para a reflexão, pois, sendo uma arte integralmente temporal, as impressões que ela elabora são transitórias. Com isso, segundo a hierarquia elaborada pelo filósofo, se

se apreciar o valor das belas-artes segundo a cultura que elas alcançam para o ânimo e tomarmos como padrão de medida o alargamento das faculdades que na faculdade de julgar têm de concorrer para o conhecimento, então a música possui entre as belasartes o último lugar [...] porque ela joga apenas com sensações (Kant, CFdJ, §53).

Em uma perspectiva oposta, no entanto, a música não seria a arte com a menor capacidade epistemológica, mas aquela que revela os limites máximos do pensamento, como se a força dionisíaca da música evidenciasse aquilo que os conceitos não são capazes de compreender, como apontaria Nietzsche em “O Nascimento da Tragédia”. De ambas as perspectivas, no entanto, a relação da música com o pensamento racional é suspeita.

É sob a luz dessa potência que podemos compreender a afirmação do demônio, um conhecedor da arte, sobre a relação entre música e teologia:

Pelo menos aprecia-me a qualidade de perito! Acho que o Diabo deve entender-se de música. Se não me engano, lias a pouco um livro daquele cristão apaixonado pela Estética. Ele, sim, estava a par do assunto e conhecia muito bem minha relação com essa linda arte - a mais cristã de todas, na opinião dele - porém, obviamente, julgava-a de modo negativo, como uma arte instituída e desenvolvida pelo cristianismo, mas rejeitada e proscrita por pertencer ao feudo do Demônio. Estás vendo? A música é uma matéria altamente teológica, da mesma forma que o pecado, da mesma forma que eu. $\mathrm{O}$ amor do cristão a ela é uma paixão genuína, porque une o conhecimento e a corrupção. A verdadeira paixão existe tão-somente nos domínios do ambíguo e sob o prisma da ironia. O mais extremo fervor dedica-se ao que é totalmente suspeito... Não, meu caro, sem dúvida alguma, sou musical. Podes acreditar. E justamente eu acabo de assumir o 
papel do pobre Judas, exibindo-te as dificuldades nas quais se embrenhou a Música, como todas as artes na atualidade. Deveria eu abster-me disso? Mas somente o fiz a fim de mostrar-te que tens vocação para ultrapassá-las, elevando-te acima delas, até ao cume da vertiginosa admiração a ti mesmo, e realizando façanhas que te causarão o mais sublime terror (Mann, 2000, p. 341).

A crise da modernidade é apontada definitivamente pelo demônio. Por meio de uma análise sócio-histórica aguda, o diabo aponta como as condições existenciais da modernidade forçam a forma estética a um impasse:

Mas no fundo, talvez concordes comigo em que a identificação dos fatos desta hora da História universal não deva ser qualificada nem de sentimental nem de maldosa. Certas coisas não são mais possíveis. A aparência dos sentimentos sob a forma da composição artística, a aparência auto-suficiente da própria Música tornaram-se impossíveis e insustentáveis (Mann, 2000, p. 241).

Compor se tornou difícil demais porque o princípio de unidade orgânica que formava a música tonal foi corrompido pelas condições materiais do século XX. No campo musical, a crise que Leverkühn enfrenta é uma extensão da frustração de Beethoven na composição de suas últimas fugas, como é bem elaborado por Kretzschmar, o professor de música de Adrian Leverkühn, especialmente no capítulo VIII do romance. A crise da tonalidade, expressa na "Sonata Opus 111" de Beethoven, tem sua expressão máxima nessa crise da qual fala o demônio e que é vivida por Leverkühn. Nesse momento, o compositor não tem mais acesso aos princípios harmônicos disponíveis na época de Beethoven, e apenas com um apelo neo-romântico ele poderia insistir nisso, alcançando um resultado fraudulento. Metamorfoseado em um intelectual, cuja descrição remeteria a Adorno ou Mahler, o demônio elabora essa condição da música à época:

O acorde em sétima diminuta? Impossível! Também impossíveis certas notas de passagens cromáticas. Qualquer compositor que se preze traz consigo um cânone do que é proibido, das interdições que cumpre impor-se a si mesmo, esse cânone que aos poucos chega a abranger os recursos da tonalidade e, com isso, de toda a música tradicional. O cânone determina o que está errado ou se tornou chapa gasta pelo uso. Na composição concebida segundo a técnica atual, sons tonais, tríades, sobrepujam quaisquer dissonâncias, e com essa finalidade talvez possam ser utilizadas, mas só cautelosamente, in extremis, pois o choque será pior do que outrora a mais forte cacofonia. Tudo depende do horizonte técnico. $\mathrm{O}$ acorde da sétima diminuta encontra-se no seu lugar adequado e é sumamente expressivo ao começo do opus 111 . Não achas também que ele corresponde ao nível geral da técnica de Beethoven e à tensão entre o máximo de dissonância, que então se podia arriscar, e a consonância? O princípio da tonalidade e seu dinamismo proporcionam ao acorde seu peso específico. Ele perdeu-o devido a um processo histórico que ninguém conseguirá inverter. Escuta o acorde fóssil! Até mesmo sob a sua forma isolada, representa uma situação técnica geral, oposta à real. Cada som traz em si o todo e também sua história. Mas, por isso, acontece que a percepção do nosso ouvido, em matéria do justo e do errado, permanece 
inelutável e diretamente ligada a ele, a esse único acorde, que em si não está errado, porém absolutamente não tem nenhuma relação abstrata para com o nível técnico geral. Temos nesse caso uma exigência de justeza que a criação dirige ao artista. É um pouco severa, não é? Não se esgotará em breve a ação do artista na realização daquilo que está circunscrito pelas condições objetivas da produção? Em cada compasso que alguém se atreva a imaginar apresenta-se a ele como problema a situação da técnica. A cada instante, a técnica, na sua totalidade, exige dele que se submeta a ela e impõe a única resposta certa, que no momento lhe parece admissível. Chega-se então ao ponto no qual as composições do artista não vão além de resposta dessa espécie e não passam de solução de rebus técnicos (Mann, 2000, p. 337-s).

O acorde de sétima diminuta, com o qual Beethoven abrira sua revolucionária "Sonata Opus 111", teria se tornado no tempo de Leverkühn um clichê tão grande que passou a contradizer as condições materiais da época. ${ }^{6} \mathrm{O}$ diabo estaria afirmando que a forma tonal é incapaz de expressar a realidade antagonista do mundo moderno. A harmonia tradicional tornou-se uma ilusão, pois os materiais musicais devem lidar com exigências que não podiam mais sustentar. Beethoven ainda podia se apoiar na manipulação da unidade motívico-temática, cuja tarefa era realizar a síntese entre a expressão subjetiva e linguagem musical tradicional, pois esse sujeito ainda era capaz de se reconhecer em uma reconciliação de sua particularidade concreta com a coletividade abstrata da sociedade. Vivendo a exigência de uma reforma estética, Leverkühn nega um retorno simples ao sistema tonal hierárquico em favor de um sistema radicalmente novo predicado na cumplicidade não hierárquica entre as notas e uma totalidade descentralizada. Em vista de conquistar uma ruptura estética, é necessário encontrar uma forma composicional que fosse adequada ao seu próprio tempo. Nesse novo sistema, todos os tons da escala cromática teriam o mesmo valor, todos reportando igualmente à totalidade da composição, e não à relação específica com um tom dominante.

O que Leverkühn busca no pacto é a força para superar essa situação de crise. Importa destacar como, em Beethoven e em Brahms, por exemplo, a liberdade subjetiva nas composições foi conquistada com a submissão do material às exigências da forma. Ou seja, a sujeição dos impulsos subjetivos a um princípio formal - limitações e ordem auto impostas - possibilitou aos compositores alcançarem experiências expressivas inéditas, a almejada expressão artística bem-sucedida na qual estão em harmonia as expectativas subjetivas e a linguagem musical. É assim que podemos compreender a ruptura artística que Leverkühn buscava com o pacto, pois a invenção de um novo princípio

6 Isso significa que as formas estéticas, bem como as obras de arte, estão submetidas a uma dinâmica de decomposição, e, após sua morte, toda tentativa de trazer de volta à vida isso que é passado incorre em uma falsidade. 
composicional, de uma estrutura construtiva formalmente rigorosa e inédita, possibilitaria recuperar as possibilidades artísticas perdidas. Como se seguisse um exemplo histórico, esse foi o passo dado por Leverkühn: a radicalização da ordem, a imposição de um estilo estrito, no qual tudo aquilo que não se submete à ordenação deve ser suprimido. Seria essa a gênese do dodecafonismo. A doença, tanto da arte quanto do sujeito, carregaria como conteúdo a necessidade de uma nova forma musical e expressiva, bem como as condições de desenvolvimento dessa forma. No entanto, a doença motivaria a suspensão da normalidade e normatividade da vida, podendo, portanto, ser inteiramente capturada pelo demoníaco, ou originar uma nova forma de salvação. Em outros termos, poderia elaborar nova mitificação, ou apresentar algo novo, um devir histórico. E, segundo nossa leitura do romance, essas duas possibilidades estão presentes, como elaboraremos a seguir.

Durante muito tempo de sua carreira de compositor, essas novas orientações musicais, que buscavam libertar o compositor de sistemas musicais insuficientes e inadequados para a época, se reverteram em nova mitificação. A lógica totalizante da forma parece ter resultado em uma nova destinação, matematicamente determinada e, assim, o dodecafonismo de Leverkühn teria se revertido num fetichismo da forma. Podemos atentar aos efeitos desse fetichismo nas composições musicais de Leverkühn, especificamente na obra "Apocalipsis cum Figuris". Nessa música, conforme elaborada pelo narrador do romance, uma mesma estrutura composicional se repetia no coro de figuras demoníacas que traziam o apocalipse e no coro representando as infantes figuras angelicais, que prometiam salvação. O sinal da relação entre música e mal não se encontra nas aparições demoníacas que a música invoca; o que é verdadeiramente nefasto repousa na indiferença com que são tratados bem e mal, salvação e danação, demônios e anjos. Podemos ainda apontar a equiparação entre a voz humana e os instrumentos, como se a formalização radical, que desconsidera todo conteúdo particular, reduzisse os homens ao estatuto de objeto inanimado.

O dodecafonismo de Leverkühn, que fora apresentado por ele ao amigo Zeitblom como forma de atentar às exigências de um ideal democrático de igualdade entre tons, faz justamente o oposto, pois sua homogeneidade radical reduz toda singularidade a um todo indiferenciado. É apenas a totalidade que une os momentos, uma totalidade que é indiferente aos elementos atômicos tanto quanto estes são indiferentes uns aos outros. A indiferença da posição de cada nota parece fundamentar sua liberdade, mas elas são não livres, na medida em que essa totalidade em que estão instaurados é inescapável e arbitrária. Assim, submetida a esse fetiche da forma, a música torna-se avessa à possibilidade de expressar qualquer significado aos sujeitos, pois seus conteúdos tornam-se arbitrários. A integração total de seus componentes não forma uma harmonia, 
mas destrói relações significativas e impõe uma ordem autoritária. Dessa forma, o dodecafonismo poderia ser a expressão do mito, uma vez que, por meio das exigências formais, impele uma completa integração de seus conteúdos e impede a manifestação de qualquer alteridade. Aqui, os princípios composicionais criados por Leverkühn, possibilitados pela doença, repõem aquele traço característico do demoníaco na vida do Fausto: a indiferença revelada no formalismo. Mas o princípio de submissão de todos os conteúdos às exigências da forma opera na música da mesma forma que na cultura em geral. Assim, a situação de renúncia à reflexão sobre os conteúdos que guiam as diversas esferas da vida social é generalizada, pois a relação que se estabelece com esses conteúdos é formal e arbitrária.

Em outro período de sua produção musical, poderíamos notar outro comprometimento entre forma e conteúdo musical, que não reduziria essa relação a uma expressão mitificada, e parece mesmo apontar para algo novo, da ordem de uma nova reconciliação entre sujeito e objetividade artística. Aúltima composição de Adrian Leverkühn parece-nos uma expressão bem-acabada das possibilidades críticas da arte, tanto no que se refere ao seu próprio conteúdo construtivo quanto aos âmbitos sociais e artísticos mais amplos.

Herdeiro de uma tradição romântica, Schoenberg buscou uma "música absoluta", de estruturação instrumental, apartada de qualquer texto e que negasse qualquer função ritualística ou pedagógica. Essa extrema pureza foi bem designada por Eduard Hanslick ao apontar que a música era formada apenas por "formas sonoras em movimento", e expressava apenas "ideias musicais" (cf. Hanslick, 2011). Clement Greenberg aponta a música como o modelo para a compreensão do empreendimento da arte modernista ou, especificamente, da vanguarda, da qual a música dodecafônica é uma expressão maior. Ele escreve que “em razão de sua natureza 'absoluta', da distância que a separa da imitação, de sua absorção quase completa na própria qualidade física de seu meio, bem como em razão de seus recursos de sugestão" (Greenberg In Ferreira; Cotrim, 1997, p. 50), a música alçou-se primeiro àquela pureza da autonomia crítica, tornando-se modelo para que as outras artes também delimitassem seu exercício. O empreendimento de Schoenberg com o serialismo visava à autonomização extrema da música, sua pureza, tornando-a independente de qualquer ideia que fosse exterior ao empreendimento musical. É por isso que até mesmo o sistema tonal de organização do material musical deve ser superado. A tonalidade e seus modos de organização fazem referência a um tipo de "gramática dos afetos", um sistema de organização da escala cromática que predeterminava os elementos e a hierarquia entre os sons por meio de exigência de controle da dissonância, elemento irracional da música. Schoenberg produzirá a "emancipação da dissonância", ou seja, ele levará ao limite o 
empreendimento que Beethoven iniciou em sua "Sonata Opus 111", e o fará com um novo processo composicional, o dodecafonismo. Nesse processo, o compositor - Adrian Leverkühn, por exemplo - organiza o material musical sob a exigência de total transparência dessa ordenação, exigência que conduz a progressiva clarificação dos desenvolvimentos e do material da música, que, por sua vez, exige o apagamento de todo elemento excedente na obra, a eliminação de todo ornamento. Nesse processo composicional, toda distinção hierárquica é destituída, superando a dicotomia entre notas ornamentais e notas essenciais (cf. Safatle In Duarte; Safatle 2007, p. 81-ss). O processo combativo operado pelo serialismo conduz a música à crítica de todo elemento de aparência da música. No romance de Mann, essa disposição construtiva é especialmente clara no elemento motívico que homenageava Esmeralda, o qual sustentava essa destituição hierárquica:

Foi nessa ocasião que Adrian, sob a pressão de dores de cabeça, desvendava-me sua idéias de uma "composição rigorosa" derivada do modo como na canção O lieb Madel, wie Schlecht bist du melodia e harmonia ficam determinadas pela permitação de um motivo básico de cinco notas, correspondentes à simbólicas letras de $h$-e-a-e-es. O amigo fazia então com que eu avistasse o "quadrado mágico", de um estilo ou uma técnica que, de materiais idênticos, permanentes, desenvolvesse o máximo de variedade e na qual já não houvesse nada que fosse atemático, nada que não pudesse demonstrar seu caráter de variação de uma coisa imutável. Tal estilo, tal técnica, segundo se afirmava, não admitiria nenhuma nota, nem uma técnica, que não cumprisse na construção geral sua função de motivo (Mann, 2000, p. 676-s).

Nesse contexto, a música moderna passa por uma transformação de sua própria função expressiva: se antes ela expressava sentimentos e paixões mediados pela aparência e derivados de uma gramática afetiva, agora a arte expressa ideias musicais cuja ordenação manifesta todo seu processo construtivo, expressão que é um fim em si mesmo. É assim que propomos compreender a última composição de Leverkühn, "Lamentação do Doutor Fausto": uma expressão não instrumentalizada inteiramente consciente de seu lugar, a única que ainda seria capaz de comunicar legitimamente a situação da arte, e, consequentemente, do mundo. É essa sensibilidade aguçada do lamento que recupera para a música a possibilidade de resistir ao mito, de expressar toda a força crítica da doença. Serenus Zeitblom elabora essa força da última composição de seu amigo:

Uma lamentação de monstruosas dimensões, tal como esta, é - repito - necessariamente uma peça expressiva, uma obra de expressão. Com isso se torna obra de libertação, assim como a música primitiva, com a qual reata os laços, num salto por cima de séculos, desejava ser liberdade de expressar-se. Ocorre apenas que o processo dialético através do qual se realiza, na fase da evolução atingida por essa obra, a passagem do mais estrito rigor para a livre linguagem da paixão, a liberdade nascida da escravidão - ocorre 
apenas que esse processo parece agora infinitamente mais complexo, infinitamente mais surpreendente e prodigioso da sua lógica do que na época dos madrigalistas (Mann, 2000, p. 676).

A composição de Leverkühn reconhece a condição trágica de seus materiais, bem como do mundo no qual é inserida. Ela é resultado de uma enfermidade, não apenas porque seu compositor estava doente, mas porque seus materiais estão enfermos. Em uma situação perpetuamente melancólica, a única verdadeira expressão será o lamento. A composição final de Leverkühn resulta na reconstrução da expressividade em sua primeira manifestação original, a expressividade como lamento, ou seja, o grito primordial da criatura sofredora. Mas esse grito não é a manifestação puramente irracional. Pelo contrário, a conquista dessa expressividade é realizada pelo recurso a um princípio mais racional de composição. A "Lamentação do Doutor Fausto" é o trabalho mais rígido de Leverkühn, mas carrega como um eco a história da música. Isso quer dizer que a forma, apesar de sua rigidez, não opera indiferentemente, não suprime seus conteúdos particulares e a tensão que os compõe. O dodecafonismo de Leverkühn/Schoenberg não nega nem desdenha as oposições e contradições, como aquelas entre consonância e dissonância, forma e conteúdo, melodia irracional e harmonia racional. Em sua expressão acabada, a técnica dodecafônica fundamenta a incomensurabilidade de percepções contraditórias e articula a verdade da inabilidade da modernidade de escapar de contradições reais do mundo. Tudo se passa como se a melhor expressão da inautenticidade da cultura ressoasse nas dissonâncias do serialismo.

\section{Parte 3 - O sentido da doença e os limites da crítica}

Thomas Mann parece elaborar a doença como uma expressão bem-acabada de uma crise. Ela seria o limiar de algo diverso, que, portanto, pode ser um momento novo, o próprio devir, ou pode ser a intensificação dos caracteres mitificados da vida, ambiguidade apontada nas considerações sobre as diferentes composições de Leverkühn. Assim, importa melhor apreender o conteúdo da doença, ${ }^{7}$ tematizar aquilo que deriva dela, pois só assim será possível compreender se será uma postulação do mito ou uma abertura à história. Se a

7 O sofrimento e a doença no romance de Mann parecem ter a peculiar função de limiar entre o mito e o devir. Isso porque a doença não é apenas a patologia individual, mas o sinal de evidenciação de condições subjetivas e sociais, das quais pode incorrer a catástrofe ou a redenção. Nesses termos, podemos fazer confluir a tematização da doença por Thomas Mann às análises sobre a modernidade dos frankfurtianos. Axel Honneth, em seu texto "A Social Pathology of Reason: in the Intelectual Legacy of Critical Theory" (In Rush, 2004), escrevendo sobre a primeira geração da Teoria Crítica, desenvolve a ideia de que aqueles 
culpa e a destinação não compõem integralmente o sofrimento e a doença de Adrian Leverkühn, seu conteúdo efetivamente pode expressar uma resistência àquele destino, um desajuste com a vida, como se possibilitasse ver o mundo transposto, cujas contradições e falhas estão mais bem iluminadas. ${ }^{8} \mathrm{E}$ se há no sofrimento de Adrian Leverkühn esse caráter crítico, é necessário perscrutar sua força em benefício do reconhecimento da possibilidade de salvação do Fausto - e com ele da arte e do homem modernos.

A vida do moderno Fausto parece, desde a infância, dirigir-se ao inferno. A relação com os estudos, o tédio, a cefaleia e a frieza já apontavam para um destino aparentemente fechado; a passagem pela teologia e o encontro com a música parecem encerrar sua vida no mito, como se Leverkühn fosse o eleito do demônio. Nesses termos, o sofrimento - e a doença - seria rendido à força do Mesmo, da reprodução da estrutura existente, impossibilitando a experiência e o verdadeiro devir histórico. Tomado por essa perspectiva, não haveria outro lugar para a alma do Fausto senão o Inferno. Mas esses elementos não totalizam o romance. A estrutura da obra de Mann é construída a partir de elementos críticos que repõe o significado do sofrimento, fazendo-o ultrapassar a dimensão mítica. Além disso, a última noite de consciência do Fausto e a sua última composição desafiariam a inevitabilidade do destino, pois contaminam a rede mítica com elementos que lhe recusam a submissão integral. Nesses termos, o sofrimento é ressignificado, e podemos recuperar a doença de Leverkühn para reconhecer nela mais do que o mero estigma do demoníaco, encontrando ali algo que o ultrapassa, que apresenta a possibilidade de uma vida diferente daquela que se oferece com naturalidade. Sobre o conteúdo de uma doença, Thomas Mann elabora que:

Aquilo que resulta da doença é mais importante e estimulante para a vida e sua evolução do que qualquer normalidade aprovada do ponto de vista médico. A verdade é que a vida nunca prescindiu da doença, e dificilmente haverá uma afirmação mais idiota do que "a doença só pode gerar coisas doentias" (Mann, 2011, p. 125).

pensadores tematizaram de formas diversas a patologia da razão no mundo moderno, do qual o sofrimento social e psíquico do homem seriam os sintomas que possibilitariam a crítica.

8 Há nessa apresentação sobre crise e resistência uma ressonância das elaborações de Adorno em "Minima Moralia", obra escrita no mesmo período em que Mann escrevia "Doutor Fausto". Seria possível notar uma fraternidade entre as obras, que parecem partilhar do mesmo espírito formado e danificado pelas experiências alemãs do começo do século XX e que mantém uma disposição reflexiva aguda e crítica sobre seu tempo. É possível notar essa fraternidade no último aforismo da obra, no qual lemos: "O único modo que ainda resta à filosofia de se responsabilizar perante o desespero seria tentar ver as coisas como aparecem do ponto de vista da redenção. O conhecimento não tem outra luz, exceto a que brilha sobre o mundo a partir da redenção: tudo o mais se esgota na reconstrução e não passa de elemento técnico. Há que estabelecer perspectivas em que o mundo surja transposto, alienado, em que se mostrem as suas gretas e desgarramentos, como se oferece necessitado e disforme à luz messiânica (Adorno, 2008, p. 259). 
Se enfatizássemos essa perspectiva, estaríamos mais dispostos a considerar que a doença não o condenou ao inferno: Adrian Leverkühn poderia ser salvo, a graça seria maior do que o pecado e sua alma seria redimida. E a força da salvação adviria justamente por causa do sofrimento e da doença, e não apesar deles.

\section{Referências}

ADORNO, T. "Filosofia da Nova Música”. Trad. M. França. São Paulo: Perspectiva, 2004. . "Minima Moralia - Reflexões a partir da vida lesada." Trad. G. Cohn. Rio de Janeiro: Beco do Azougue, 2008.

ADORNO, T., HORKHEIMER, M. "Dialética do Esclarecimento". Trad. G. d. Almeida. Rio de Janeiro: Jorge Zahar, 1985.

AUERBACH, E. "Mimesis: a representação da realidade na literatura ocidental". V. Tradutores. São Paulo: Perspectiva, 2009.

BARRENTO, J. "Fausto na Literatura Europeia”. Lisboa: Apáginastantas, 1984.

BENJAMIN, W. "Escritos sobre Mito e Linguagem". J. M. Gagnebin, Ed., S. K. Lages, Trads. E. Chaves. São Paulo: Duas Cidades; Ed. 34., 2011.

BERGSTEN, G. "Thomas Mann's "Doctor Faustus" - The sources and Structure of the Novel". Trad. K. Winston. Chicago: University of Chicago Press, 1969.

BLOOM, H. "Thomas Mann - Modern Critical Views". New York: Chelsea House Publishers, 1986.

DAHLHAUS, C. "Schoenberg and the new musica". Cambridge: Cambridge University Press, 1987.

DUARTE, R., SAFATLE, V. “Ensaios sobre Música”. São Paulo: Humanitas, 2007. GALLE, H., MAZZARI, M. "Fausto e a América Latina". São Paulo: Humanitas, 2010. GREENBERG, C. "Estética Doméstica". Trad. A. Carone. São Paulo: Cosac \& Naify, 2002.

HANSLICK, E. "Do Belo Musical”. Lisboa: Edições 70, 2011.

KANT, I. “Crítica da Faculdade de Julgar”. Petrópolis: Vozes, 2016.

KRAUS, J. Expression and Adorno's Avant-Garde: The Composer in "Doktor Faustus". The German Quarterly, Vol. 81, Nr. 2, pp. 170-184, Primavera de 2008. Disponível em: http://www.jstor.org/stable/27676163.

LUKÁCS, G. “Thomas Mann”. Trad. J. Muñoz, Barcelona: Grijalbo, 1969.

MANN, T. "Essays of Three Decades". Trad. H. T. Lowe-Porter. New York: Alfred A. Knopf, 1947.

. "A Montanha Mágica". Trad. H. Caro. Rio de Janeiro: Nova Fronteira, 1980.

. "Die Betrogene". In: T. Mann, Sämlitche Erzählungen in zwei Bänden (Vol. II, pp. 1038-1121). Darmstadt: S. Fischer Verlag, 1987a.

. "Reflections of a Nonpolitical Man". Trad. W. Morris. New York: Ungar, 1987b. "Doutor Fausto: a vida do compositor Adrian Leverkühn narrada por um

amigo". Trad. H. Caro. Rio de Janeiro: Nova Fronteira, 2000a. 
. "Schopenhauer, Nietzsche, Freud". Trad. A. S. Pascual. Madrid: Alianza, 2000b. . “A Enganada”. In: T. Mann, Duas Novelas. Trad. L. Luft (pp. 91-174). São Paulo: Mandarim, 2001a.

. "A Gênese do Doutor Fausto - Romance de um Romance". Trad. R. Henrique. São Paulo: Mandarim, 2001.

."Doktor Faustus" (Vol. 1). Ed. R. Wimmer. Frankfurt: S. Fischer Verlag, 2007a. . "Doktor Faustus - Kommentar" (Vol. 2). Ed. R. Wimmer. Frankfurt: S. Fischer Verlag, 2007b.

. "O Escritor e sua Missão". Ed. J. Kretschmer, Trad. K. Michahelles. Rio de Janeiro: Zahar, 2011.

MATOS, O. "Discretas Esperanças". São Paulo: Nova Alexandria, 2006.

NIETZSCHE, F. “Obras Incompletas - Coleção Os Pensadores”. Trad. R. R. Torres Filhos. São Paulo: Abril Cultura, 1978.

. "Além do Bem e do Mal". Trad. P. C. Souza. São Paulo: Companhia das Letras, 1992.

. “A Gaia Ciência”. Trad. P. C. Souza. São Paulo: Companhia das Letras, 2001. . "O Nascimento da Tragédia". Tard. J. Guinsburg. São Paulo: Companhia das Letras, 2007.

PALMER, P. M., MORE, R. P. "The Sources of the Faust Tradition: from Simon Magus to Lessing". London, New York: Oxford University Press, 1936.

REED, T. J. "Thomas Mann - The Uses of Tradition". Oxford: Oxford University Press, 1996.

RÖCKE, W. “Thomas Mann Doktor Faustus 1947-1977”. Bern: Peter Lang, 2004.

ROSENFELD, A. “Thomas Mann”. Campinas, SP: Perspectiva, 1994.

RUSH, F. “Cambridge Companion To Critical Theory”. New York: Cambridge University Press, 2004.

SAFATLE, V. "Cinismo e a Falência da Crítica”. São Paulo: Boitempo, 2008.

WEBERN, A. "The Path to the New Music". Trad. W. Reich. Pennsylvania: Theodore Presser, 1963. 